\title{
Study on the Upset Welding of Shear Reinforcement with Large Diameter*
}

\author{
by KOHEI HAYASHI **, HIDENORI TERASAKI ${ }^{* *}$, YU MIYAHARA **, MANABU TANAKA ***, \\ KYOHEI KONISHI ${ }^{* * *}$, HIROSHI INOUE ${ }^{* * * *}$ and YOSHINOBU HAYASHI ${ }^{* * * * *}$
}

\begin{abstract}
In the current standard, diameters of upset weldable steel bar are restricted $16 \mathrm{~mm}$ or less. In this study, we visualized the changes of welded part and the changes of temperature in the upset welding by using a high-speed camera. The specimens used in the experiment are SD390 steels with diameters of $19 \mathrm{~mm}$ or more. Thus, in the upset welding of shear reinforcement with diameter of $32 \mathrm{~mm}$, it is possible to achieve a $100 \%$ joint efficiency by ensuring the optimum Joule heat by adjusting the welding pressure and the electric current. The two-color thermometry revealed that ensuring the joining temperature range $\left(1300^{\circ} \mathrm{C}-1400^{\circ} \mathrm{C}\right)$ is important to secure the safe welding.
\end{abstract}

Key Words: Upset welding, Welding phenomena, Temperature distribution, Diameter of bar, Electric current, Welding pressure, Shear reinforcement, SD390

\section{Introduction}

Shear reinforcement restrains the progress of diagonal cracks and is also considered important from the perspective of resistances to the shear force and the compression in situations such as preventing shear fractures and restraining the buckling of main reinforcements where a stable quality of shear reinforcement is required. Therefore, manufacturing steel bars using upset welding is effective because of its high processing accuracy, highly efficient construction, and good shape-retention of steel bars. Moreover, upset welding can be applied to high-strength bars.

In recent years, increasing the diameters of shear reinforcements has become necessary to improve the strength of high-rise buildings. However, technical literature ${ }^{1)}$ states that the diameters of upset-weldable steel bars welded in factories are restricted to $16 \mathrm{~mm}$ or less as per current standards. Therefore, further development of technologies is required in order to allow upset welding for shear reinforcements with larger diameters; this requires understanding the phenomena associated with upset welding.

Previous studies have compared the differences in tensile strengths of joints ${ }^{2-5)}$ obtained on changing welding conditions such as electric current ${ }^{2-5)}$, welding time ${ }^{2-5)}$, welding pressure ${ }^{4-5)}$, and heat input ${ }^{4}$. Certain other studies have also observed the microstructures of specimens in a heat-affected zone after welding ${ }^{4-6)}$. However, the diameters of the steel bars in these

\footnotetext{
${ }^{*}$ Received: 2016.10 .17

** Graduate School of Science and Technology, Kumamoto University

${ }^{* * *}$ Joining and Welding Research Institute, Osaka University

${ }^{* * * *}$ Kansai Law \& Patent Office

${ }^{* * * * *}$ Keishin Kougyou
}

studies were approximately $10-16 \mathrm{~mm}$, and no study focused on increasing the diameters of the steel bars.

In the present study, the upset welding process of steel bars with diameters larger than $19 \mathrm{~mm}$ and their corresponding temperature distributions were observed. We also reported the factors required for successful upset welding of shear reinforcements with diameters of up to $32 \mathrm{~mm}$.

\section{Experimental methods}

\subsection{Specimens and welding conditions}

The specimens were SD390 steels, the chemical composition of which is presented in Table 1. As shown later, the conditions of upset welding for shear reinforcement with a diameter of $32 \mathrm{~mm}$ that can achieve $100 \%$ joint efficiency were proposed (electric current: $10.3 \mathrm{kA}$, welding pressure: $0.8 \mathrm{MPa}$ ). Based on these conditions, a pressure-shortage condition (electric current: 10.3 $\mathrm{kA}$, welding pressure: $0.5 \mathrm{MPa}$ ) was also intentionally tested and the differences in welding phenomena between the two conditions were observed.

Table 1 Chemical composition of SD390 steel

\begin{tabular}{|c|c|c|c|c|c|c|}
\hline & $\mathrm{C}(\mathrm{mass} \%)$ & $\mathrm{Si}(\mathrm{mass} \%)$ & $\mathrm{Mn}(\mathrm{mass} \%)$ & $\mathrm{P}($ mass\%) & $\mathrm{S}(\mathrm{mass} \%)$ & $\mathrm{C}+\mathrm{Mn} / 6$ \\
\hline $\mathrm{SD} 390$ & 0.27 & 0.21 & 1.0 & 0.031 & 0.027 & 0.44 \\
\hline
\end{tabular}

\section{$2.2 \quad$ Two-color thermometry}

During the welding process, two-color thermometry was performed using a high-speed camera, and we attempted the visualization of the upset welding process and its corresponding temperature distribution. In this experiment, a miroEX camera and a SIGMA DG 28-300 lens were used. The focal length was 
$300 \mathrm{~mm}$ and the temperature range was $1300{ }^{\circ} \mathrm{C}-2300^{\circ} \mathrm{C}$. Videos were taken with a frame rate of $100 \mathrm{fps}$, and the brightness was adjusted using the diaphragm. Using a high-speed camera is possible to confirm the instantaneous behavior of the object. Furthermore, radiation of red and green wavelengths was measured, and the G/R intensity ratio was used for comparing the luminance of two wavelengths in the two-color temperature method.

\section{Result and discussion}

Figs. 1 and 2 show photographs of the welding (left) and the temperature distribution (right) derived from two-color thermometry. The images were taken using the high-speed camera in the proposed and pressure-shortage conditions for SD390 steels with a diameter of $32 \mathrm{~mm}$. In the proposed condition, extreme temperature changes were not seen, a temperature of between $1300{ }^{\circ} \mathrm{C}$ and $1400{ }^{\circ} \mathrm{C}$ could be confirmed, and the welded part was smoothly swelled. When we joined using conditions with suitable welding pressure and electric current, the change in the cross-sectional area with time allowed the administration of the optimal Joule heat to the welded part. In the pressure-shortage condition, it could be confirmed that many parts exceeded $1500^{\circ} \mathrm{C}$ and the cross-sectional area of the welded part before deformation was small. In the welded part, features such as flower blooms could be observed under excessive heating.
If the state of the welded part at $20 \mathrm{~s}$ in Fig. 1 is compared with that at $20 \mathrm{~s}$ in Fig. 2, it can be seen that the cross-sectional area of the welded part for the pressure-shortage condition is smaller than that for the proposed condition. Therefore, it is considered that the resistance of the pressure-shortage condition is larger than that of the proposed condition, and it can be said that the large Joule heat in the pressure-shortage condition also increases temperature rise relative to the proposed condition. Therefore, the welded part for the pressure-shortage condition is considered to exhibit welding features such as flower blooms because the welded part melts.

Fig. 3 shows photographs after tensile tests of specimens prepared using the proposed and pressure-shortage conditions for SD390 steels with a diameter of $32 \mathrm{~mm}$.

Using the proposed condition, a form with ductile fracture of a typical cup and cone type was confirmed and specimens were fractured at the base material. Furthermore, using the pressure-shortage condition, a form with regional shearing deformation was confirmed in the heat-affected zone.

Fig. 4 shows element distribution map of oxide for (a) proposed condition (b) pressure-shortage condition in cross-sectional view. It was clear that smooth weld was formed in proposed-conditions and oxide did not remain in the weld. On the other hand, in the case of pressure-shortage condition, weld shape was not smooth and a lot of oxide remained in the weld. It is due to the poor expulsion of oxide in the pressure-shortage condition. It caused regional shearing deformation in the heat-affected zone.
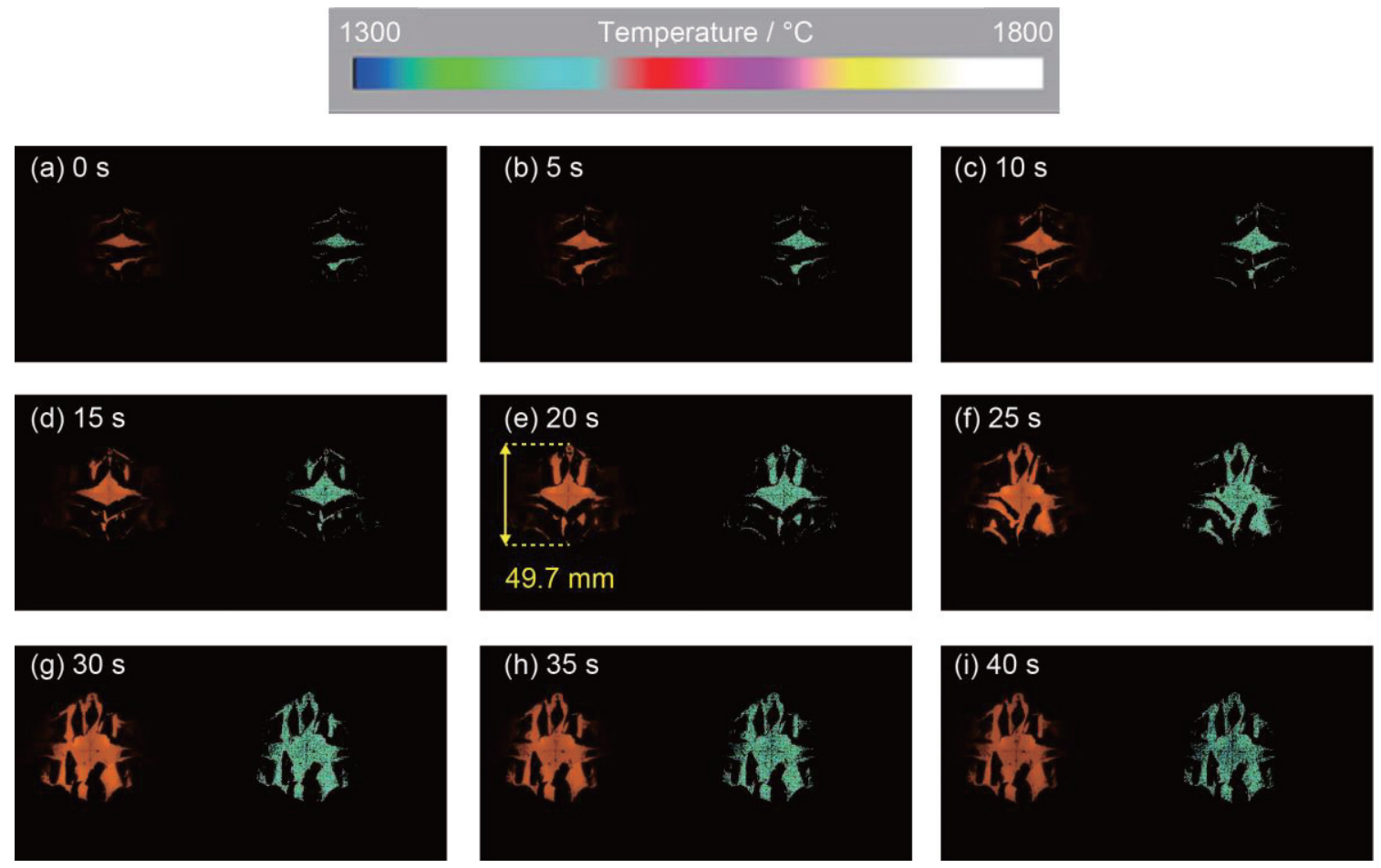

Fig. 1 Photographs of the welding (left) and the temperature distribution derived from two-color thermometry (right) (Proposed condition) 

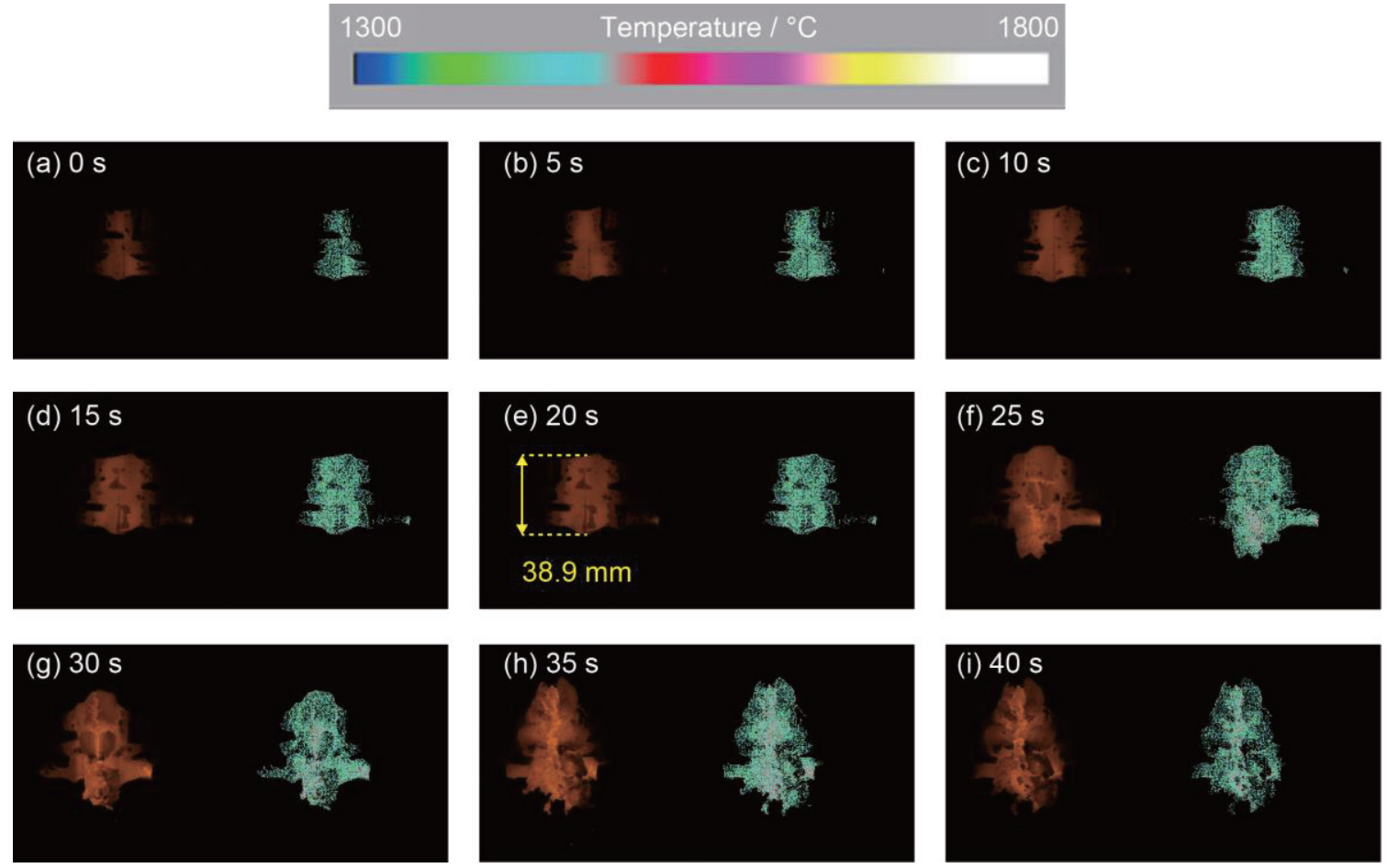

Fig. 2 Photographs of the welding (left) and the temperature distribution derived from two-color thermometry (right) (Pressure-shortage condition)
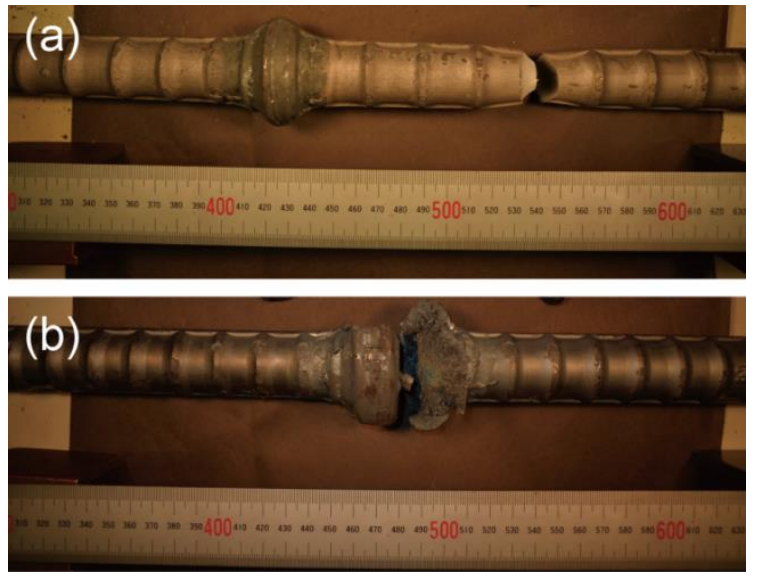

Fig. 3 Result of tensile test

(a) Proposed condition (b) Pressure-shortage condition
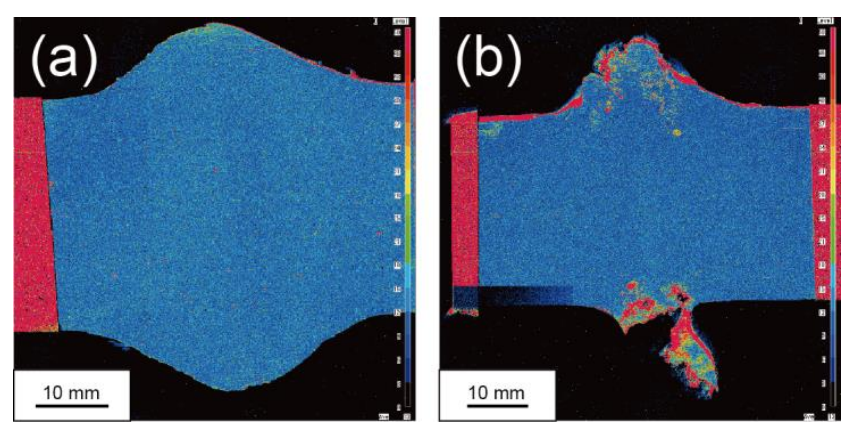

Fig. 4 Element distribution map of oxide

(a) Proposed condition (b) Pressure-shortage condition
As described above, if the diameter of the bar after joining is properly maintained, then proper upset welding is possible, even with diameters of $16 \mathrm{~mm}$ or more. To quantify the optimal "diameter of joint," Fig. 5 summarizes the minimum and maximum values of the diameter of the bar after joining using the proposed condition (joint efficiency of 100\%) and the pressure-shortage condition for SD390 steel with diameters of 16 $\mathrm{mm}$ or more.

From the results of Fig. 5, when a sound welded part was formed, "diameter of joint" was confirmed to exist in the approximately linear region against the diameter of the bar. In Fig. 5 , the blue line is the proposed condition and the red line is the pressure-shortage condition. The latter result is affected by a feature such as flower blooms as shown in Fig. 2. From Fig. 5, it can be seen that there is a narrow region of optimal "diameter of joint." If the average value of "diameter of joint" for the proposed condition for SD390 steel is approximated with least squares, the following equation is obtained relating the diameter of the bar, D $(\mathrm{mm})$, and the "diameter of joint," $\mathrm{F}(\mathrm{mm})$.

$$
\mathrm{F}=4.3619+1.4708 \mathrm{D} \cdots(1)
$$

The above results mean that a sound joint can be formed regardless of the diameter of the bar in upset welding by ensuring that "diameter of joint" satisfies equation (1). 


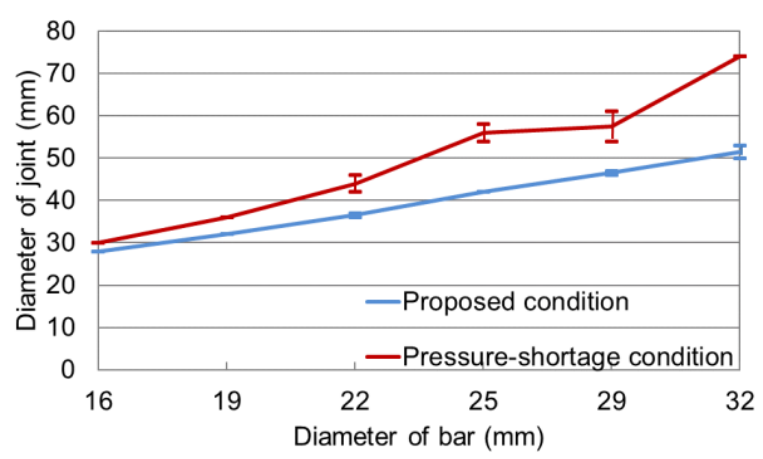

Fig. 5 Diameter of joint against diameter of bar in proposed and pressure-shortage conditions

\section{Conclusions}

The principles and phenomena of upset welding were investigated in the present study. The results of the study can be summarized as follows:

In the upset welding for shear reinforcement with diameters of $32 \mathrm{~mm}$, which was previously thought to be impossible, it is possible to achieve a $100 \%$ joint efficiency if the optimum Joule heat is ensured by adjusting the pressure and electric current.

In the upset welding for shear reinforcement of SD390 with diameters of 22-32 $\mathrm{mm}$ using the proposed and pressure-shortage conditions, welding phenomena were revealed by visualization of the welding process and its corresponding temperature distribution. Using the proposed condition, the welded part smoothly swelled because optimum Joule heat was provided, and temperatures between $1300{ }^{\circ} \mathrm{C}$ and $1400{ }^{\circ} \mathrm{C}$ were observed in the welded part. Using the pressure-shortage condition, the welded part exhibited welding features such as flower blooms due to excessive heating, and the welded part frequently exceeded $1500{ }^{\circ} \mathrm{C}$. Two-color thermometry revealed that ensuring the proper joining temperature range $\left(1300-1400{ }^{\circ} \mathrm{C}\right)$ is important for securing safe welding.

\section{Acknowledgements}

This Work was performed under the Joint Usage/Research Center on Joining and Welding, Osaka University.

\section{Reference}

1) Japan Society of Civil Engineers, “Recommendations for Design, Fabrication and Evaluation of Anchorages and Joints in Reinforcing Bars" (2007), 195-198

2) M. Hamedi, Journal of Achievements in Materials and Manufacturing Engineering, Vol. 17 (2006) ,341-344

3) Mohsen Hamedi, Hamid Eisazadeh, Mousa Esmailzadeh, Materials and Design 31 (2010), 2296-2304

4) M. Sharifitabar, A. Halvaee, S. Khorshahian, Materials and Design 32 (2011), 3854-3864

5) Mahmood Sharifitabar, Ayyub Halvaee, Materials and Design 31 (2010), 3044-3050

6) Soo-Sung KIM, Geun-Il PARK, Jung-Won LEE, Jin-Hyun KOH and Choon-Ho PARK, Journal of NUCLEAR SCIENCE and TECHNOLOGY, Vol. 47 (2010), No. 3, 262-268 